\section{Obesity, diabetes and periodontitis - a triangular relationship?}

\author{
R. S. Levine ${ }^{1}$
}

VERIFIABLE CPD PAPER
IN BRIEF
- Reports that the increasing prevalence of type 2 diabetes will impact on oral health, especially periodontitis.
- Reviews recent research suggesting a three-way metabolic relationship between obesity, diabetes and periodontal disease.
- Suggests periodontitis may adversely affect glycaemic control in diabetics but can be improved by periodontal treatment.

The global rise of obesity, both adult and childhood, has been paralleled by a rise in type 2 diabetes, a trend predicted to continue for at least the next two decades. The combined effect will create a burden of direct and co-morbidities that will strain the physical and financial resources of all countries. While it is accepted that both type 1 and type 2 diabetes are major risk factors for the development and progression of periodontal disease, there is growing evidence that obesity is both an indirect risk factor because it affects glycaemic control and a direct risk factor because secretion of pro-inflammatory agents by adipose tissue modifies the periodontal reaction to the plaque biofilm. Recent research suggests that periodontitis may adversely affect glycaemic control, which can be improved by periodontal treatment with reduced risk of diabetic co-morbidity, thereby creating a two-way relationship. Furthermore it appears possible that periodontitis may stimulate inflammatory change in adipose tissue, creating a triangular self-generating cycle of morbidity linking obesity, diabetes and periodontal disease. Dentists should recognise these interlinked risk factors and consider including an assessment of glycaemic control and adiposity, possibly by waist-to-hip ratio, when periodontitis is diagnosed and in collaboration with medical practitioners provide treatment to help reduce the development of systemic disease.

\section{BACKGROUND}

There is now little doubt that the increasing worldwide prevalence of obesity is leading to increased morbidity, especially cardiovascular disease, diabetes and cancer. It is predicted that this trend will result in 65 million more obese adults in the USA and 11 million more obese adults in the UK by 2030, together leading to an additional 6-8.5 million cases of diabetes, 5.7-7.3 million cases of heart disease and stroke and 492,000-669,000 additional cases of cancer. By 2030 the combined medical costs for these preventable diseases alone are estimated to increase by \$48-66 billion per year in the USA, impacting on health insurance premiums and by £1.9-2.0 billion per year in the UK, where the burden will fall largely on the state. ${ }^{1}$ In the UK, a recent study estimates that by 2035 the direct and indirect cost

Department of Oral Surgery, Leeds Dental Institute and Academic Unit of Obstetrics, Gynaecology and

Paediatrics, University of Leeds

Correspondence to: Dr R. S. Levine OBE

Email: r.s.levine@leeds.ac.uk

\section{Refereed Paper}

Accepted 9 May 2013

DOI: 10.1038/sj.bdj.2013.627

British Dental Journal 2013; 215: 35-39 of diabetes to the NHS will have risen to over $£ 40$ billion per year at today’s values. ${ }^{2}$

There is substantial evidence for a relationship between overweight/obesity and type 2 diabetes $^{3}$ and although this condition was often called 'late onset diabetes' we are now seeing increasing prevalence in young people. ${ }^{4-6}$ There is also evidence for a relationship between both type 1 and type 2 diabetes and the chronic destructive condition of the dentition - periodontitis, recognised over 60 years ago. ${ }^{78}$ More recently evidence has emerged for a relationship between overweight/obesity and periodontal disease, although an excellent systematic review by Suvan et al. indicates that the magnitude is unclear. ${ }^{9}$ While there is evidence for these relationships, a causal basis has been assumed but is not established. The aims of this paper are firstly to examine the evidence for an underlying mechanism linking obesity, diabetes and periodontal disease and the interaction between these three conditions so as to gain a better understanding of what might now be viewed as a triangular relationship. Secondly, to highlight for dental practitioners the clinical significance of these relationships for the prevention and treatment of periodontal disease and the role they should play in helping to reduce the burden of related systemic disease.

\section{OBESITY AND DIABETES}

Systemic medical conditions associated with an increase in body weight and specifically adiposity are now well recognised. They include type 2 (insulin resistant) diabetes, cardio-vascular disease and osteoarthritis. Excessive body weight was recognised as a potential cause of diabetes over a century ago and since then the mass of accumulated research has confirmed this association and epidemiological studies have shown a parallel increase in both. ${ }^{10}$ It has been estimated that obese persons have a more than ten-fold increased risk of developing type 2 diabetes compared with normal-weight persons ${ }^{11}$ and one study has put the increased risk for women with a BMI of 35 or greater at 93-fold. ${ }^{12}$ Diabetes was estimated to affect about 250 million people worldwide in 2007, a figure predicted to rise to 350 million by $2030,{ }^{13}$ the impact of which has been likened to a health tsunami. ${ }^{14}$ It is now one of the most common non-communicable diseases globally. It is the fourth or fifth leading 
cause of death in most developed countries and there is substantial evidence that it is endemic in many developing and newly industrialised nations. Complications from diabetes, such as coronary artery and peripheral vascular disease, stroke, diabetic neuropathy, amputations, renal failure and blindness are resulting in increasing disability, reduced life expectancy and enormous direct and indirect health costs.

During the last 15 years research work has focused on unravelling the underlying biochemical mechanism linking adiposity with type 2 diabetes. Adipose tissue is no longer considered as merely a depository of fat containing cells but is now seen as an active endocrine organ with adipocytes, like many other cells, capable of releasing hormones, the best known being leptin, the appetite controlling hormone and cytokines. These small proteins with a typical molecular weight in the range 8,00040,000 , which are related not by structure but by their common cellular signalling action, including the regulatory mechanism that determines the body's reaction to cellular trauma and infection by either promoting or suppressing the inflammatory response. ${ }^{15}$ Adipocyte secreted cytokines, now referred to as adipokines, released into the circulation appear to have the ability to mediate and modulate inflammatory activity. The adipokines most implicated as proinflammatory mediators are interleukin 6 (IL-6) and tumour necrosis factor (TNFa). Accumulating evidence now suggests that excessive adiposity can promote chronic low-grade inflammation leading to the systemic metabolic disturbance associated with obesity-linked disorders. The abnormal or excessive secretion of adipokines appears to be one mechanism in the pathogenesis of obesity-linked morbidity. ${ }^{16}$

Several factors have been proposed to explain increased insulin resistance in the obese populations, beginning with increased free non-esterified fatty acids (FFA) accumulation, increased secretion of inflammatory cytokines and adipokines leading to C-reactive protein (CRP) secretion, and mitochondrial dysfunction, all implicated in insulin resistance and pancreatic $\beta$-cell dysfunction. While these suggestions are still being evaluated and the complexity of possible mechanisms is becoming more apparent, there is growing evidence that part of the underlying mechanism is related to adipocyte production of adipokines ${ }^{11}$ including IL-6 and TNFa. ${ }^{16}$ The basis of this suggestion is two-fold. Firstly, there is evidence that adipokine production mirrors increased adiposity and secondly that circulating adipokines have been found in higher concentrations in the type 2 diabetic population. ${ }^{16}$ While this evidence does not establish a causal relationship, the epidemiological data showing a parallel rise in obesity and type 2 diabetes prevalence, both accompanied by raised levels of circulating pro-inflammatory cytokines, reinforces the belief in an inflammatory mediated metabolic mechanism.

The generally accepted mechanism is that a high calorie diet leading to an over-accumulation of fatty acids in adipose tissue induces adipocyte hypertrophy and increases the production of reactive oxygen species (ROS) leading to the activation of adipose tissue inflammation and increased expression of cytokines. Upregulation of cytokines stimulates the infiltration of chronic inflammatory cells such as macrophages. These cells further accelerate inflammation by secreting more pro-inflammatory cytokines and chemoattractants (chemokines) causing further infiltration of chronic inflammatory cells and a further rise in pro-inflammatory adipokine secretion, thus initiating a selfgenerating reciprocal cycle of chronic inflammation. Increased levels of circulating FFA, ROS and inflammatory cytokines disrupt insulin signalling in organs such as skeletal muscle and the liver, leading to $\beta$ cell dysfunction, systemic insulin resistance and the onset of diabetes mellitus. ${ }^{17,18}$

\section{OBESITY AND PERIODONTAL DISEASE}

Chronic periodontal disease is characterised by a progressive destruction of the periodontal ligament and alveolar bone supporting the teeth. The initial inflammatory reaction is seen at the gingival margin and appears to be related in part to bacterial plaque accumulation, however, the subsequent progressive destruction appears dependent upon a complex plaque-host relationship that is still being investigated.

The first report on the relationship between obesity and periodontal disease appeared in 1977, when Perlstein et al. found alveolar bone resorption to be greater in obese rats compared with nonobese rats. ${ }^{19}$ Further evidence was provided by a survey of older people in the UK. ${ }^{20}$ Two literature reviews provide evidence linking obesity with periodontal disease. ${ }^{21,22}$ While this evidence is supported by recent studies from Korea, ${ }^{23}$ Jordan $^{24}$ and Finland, ${ }^{25}$ a recent four-year follow-up of 396 Finnish adults found no significant association between body mass index (BMI) and deepened periodontal pockets. ${ }^{26}$ An analysis of data from the United States third National Health and Nutrition Examination Survey (NHANES III) showed a significant correlation between body composition and periodontal disease for adults with waist-to-hip ratio being most significant, followed by BMI, free fat mass and subcutaneous fat. ${ }^{27}$ Several studies have indicated that abdominal fat (central adiposity) rather than subcutaneous fat is more strongly associated with periodontitis. ${ }^{27-29} \mathrm{~A}$ further analysis from the NHANES III dataset showed that only in the 18 to 34 year age group, were measures of body fat associated with periodontal disease, while underweight (BMI <18.5) was associated with decreased prevalence ${ }^{29}$ An analysis of data from 2,452 non-smokers in the NHANES III survey showed that adolescents aged 17-21 years had an increased risk of periodontitis for each $1 \mathrm{~kg} / \mathrm{m}^{2}$ increase in body mass index and for each $1 \mathrm{~cm}$ increase in waist circumference. $^{30}$ In a study of 706 Brazilian adults where $60 \%$ and $65 \%$ of males and females, respectively, were overweight or obese, obesity was significantly associated with periodontitis in adult, non-smoker women, but not in men. ${ }^{31}$ Recently reported studies have shown a similar relationship between BMI and periodontal disease in young people $^{32,33}$ and this is a grave concern.

Although most evidence has come from cross-sectional data, strong evidence has come recently from three longitudinal studies in the USA, one showing significant periodontal disease progression over 25 years in obese men ${ }^{34}$ and the second, a very large study of 36,910 health care professionals showed a significant association, even among the non-diabetic and neversmoking over a period of up to 20 years. ${ }^{35}$ In a third study a five-year follow-up of 3,590 Japanese subjects showed evidence of a dose-response association between 
BMI and periodontal disease.$^{36}$ While much evidence suggests that it is the predisposition to type 2 diabetes that links obesity to periodontal disease, a large USA longitudinal study ${ }^{30}$ and a large Finnish survey of non-diabetic, non-smoking adults showing an association between BMI and periodontal pocket depth ${ }^{26}$ do not support the hypothesis of a direct causal chain, but suggest the involvement of other factors (vide infra).

While a metabolic basis for a direct causal relationship between obesity and periodontitis remains to be confirmed, it is possible that increased secretion of mediators of inflammation may modify the response of the periodontal tissues to the oral environment and the excessive production of adipokines could produce this effect. There is evidence linking periodontal disease with metabolic disorder, an increasingly common loose association of abdominal obesity, abnormal fat metabolism, hypertension, insulin resistance, high plasma fibrinogen and elevated CRP. This strengthens arguments that periodontal disease and certain obesity-related systemic illnesses are related through an inflammatory mechanism, with abnormal fat metabolism possibly being an important factor.

\section{DIABETES AND \\ PERIODONTAL DISEASE}

Diabetes as a risk factor for periodontal disease has been recognised for over 60 years. ${ }^{5,7,8}$ In the 1990 s studies on the Pima Indians, a genetically cohesive community living in the Gila River Indian Reservation in Arizona, demonstrated that periodontitis is more prevalent in diabetic patients and worsens with diabetes $;^{37}$ and in 1993 the distinguished periodontologist Harald Löe described periodontitis as the sixth complication of diabetes. ${ }^{38}$ There is now a considerable weight of evidence establishing diabetes as a risk factor for chronic periodontitis, especially where glycaemic control is poor ${ }^{39.40}$ and the increased risk has been estimated at threefold..$^{41}$ This appears to be true also for type 1 diabetes and there is evidence for increased risk of periodontal disease in affected children. ${ }^{5,42,43}$

A clearer picture of the metabolic basis for the relationship between diabetes and periodontal disease has begun to emerge in the last 20 years. Diabetes appears to disturb the macrophage properties of chronic inflammatory cells, impeding the response to bacterial infections and wound healing. ${ }^{44}$ Recent attention has focused on the role of advanced glycation end products (AGEs). In the hyperglycaemic state found in diabetics, glycation and oxidation of proteins and lipids occurs resulting in the accumulation of AGEs. ${ }^{45}$ Receptors for AGEs (RAGE) are found on endothelial cells and chronic inflammatory cells. The discovery that RAGE was a receptor for S100/calgranulins inflammatory proteins and high mobility group box 1 (HMGB1), an intracellular protein that can programme macrophages to secrete cytokines, set the stage for linking RAGE to be both a consequence and cause of types 1 and 2 diabetes. ${ }^{46}$ It is the reaction between AGEs and their cellular receptors (RAGE) that has been linked to increased ROS production and cellular and matrix changes, including abnormal endothelial cell function and in the increased vascularity seen in the inflammatory complications of diabetes. Secretion of pro-inflammatory cytokines such as IL-1 $\beta$, IL-6 and TNFa also appear to be increased by AGE/RAGE reaction and raised levels have been found in gingival crevicular fluid of diabetics compared to healthy subjects. ${ }^{41}$

\section{A TRIANGULAR RELATIONSHIP?}

In recent years there has been increasing evidence for a two-way relationship between diabetes and periodontal disease, suggesting not only that diabetes exacerbates the inflammatory response to plaque accumulation, but that periodontal inflammation can impair glycaemic control ${ }^{47-51}$ and may predict the development of diabetes in non-diabetic subjects. ${ }^{52}$ The basis for this is partly a better understanding of the metabolic processes linking diabetes and inflammation, supported by evidence that periodontal treatment can result in a reduction in plasma glycated haemoglobin (HbA1c), and improved glycaemic control for diabetic patients. ${ }^{53}$ As for the association between obesity and periodontal disease, a recent systematic review and meta-analysis found strong evidence for a direct association, but not for a direction for the association and so was unable to establish to what extent obesity exacerbated periodontal disease or the converse. ${ }^{22}$ A recent study from Japan found that obesity in women was associated with more severe periodontitis independent of their glucose tolerance, suggesting a direct link not dependent on diabetic status. ${ }^{54}$ It is possible that as well as a direct effect on glycaemic control, periodontal inflammation can disturb fat metabolism causing hyperlipidaemia ${ }^{55,56}$ and by increasing the level of circulating pro-inflammatory cytokines induce inflammatory changes in adipose tissue leading to infiltration of chronic inflammatory cells and increased secretion of adipokines. This in turn would impair glycaemic control leading to increased AGE expression, increased formation of cytokines and a further impact on periodontal inflammation. There are suggestions that gram-negative periodontal pathogens by secreting lipopolysaccharide could trigger the release of systemic cytokines, disturbing fat metabolism and causing hypertriglyceridemia. ${ }^{28,49}$ All of these suggestions point to a possible three-way relationship between adiposity, diabetes and periodontal disease with each condition influencing the others and inflammation providing the two-way conduit between each of them.

\section{CLINICAL CONSIDERATIONS}

While diabetes is now well recognised as a risk factor for periodontal disease, recent research has established obesity, especially abdominal adiposity, as a risk factor because of its impact on glycaemic control. Periodontologists are well aware of the problems in stabilising periodontal disease in diabetic patients, but there is now convincing evidence that periodontal treatment can result in reductions in HbA1c levels ${ }^{47,57,58}$ and while modest, there are clear indications that similar decreases can reduce the risk of diabetic co-morbidity and even mortality. It has been estimated that each $1 \%$ reduction in $\mathrm{HbA} 1 \mathrm{c}$ is associated with reductions in risk of $21 \%$ for deaths related to diabetes, $14 \%$ for myocardial infarction and 37\% for microvascular complications. ${ }^{59}$ In a study of Pima Indians with type 2 diabetes, periodontal disease was found to be a strong predictor of mortality from ischaemic heart disease and diabetic nephropathy and was an addition to the effects of traditional risk factors for these diseases. ${ }^{60}$ 
Given the evidence for a positive effect of periodontal treatment on glycaemic control and the link between central adiposity and poor control, the dental profession should now consider whether an assessment of adiposity and glycaemic control should be part of the clinical assessment of patients with periodontal disease. In November 2012 a consensus document following the ninth European Workshop on Periodontitis and Systemic Diseases stated that: 'Patients with diabetes should be told that they are at increased risk for periodontitis. They should also be told that if they suffer from periodontal disease their glycaemic control may be more difficult and they are at higher risk for other complications such as cardiovascular and kidney disease. Patients presenting with a diagnosis of type 1 , type 2 or gestational diabetes should receive a thorough oral examination, which includes a comprehensive periodontal evaluation. If periodontitis is diagnosed, it should be properly managed. If no periodontitis is diagnosed initially, patients with diabetes should be placed on a preventive care regime and monitored regularly for periodontal changes. ${ }^{, 61,62}$

It has been suggested that dentists should be more proactive in working with medical colleagues in diagnosing and managing diabetic patients and should consider the use of a blood glucose monitor, especially if patients complained of any of the classic symptoms of diabetes. ${ }^{63}$ By doing so dentists have the opportunity to identify unrecognised diabetes and pre-diabetes in their patients and refer them to a physician for further evaluation and care. ${ }^{64}$ It has also been suggested that periodontologists should counsel obese patients regarding the possible oral complications of obesity, as they do with smoking, and include an assessment of abdominal adiposity on a regular basis for periodontal risk assessment. ${ }^{53}$ While this can be done by calculating BMI there is evidence that waist-to-hip ratio and waist circumference are better predictors of periodontal disease $\mathrm{e}^{27,35}$ and diabetes. ${ }^{65}$ Because of evidence that the prevention and treatment of periodontal disease may reduce the risk of systemic morbidity at both individual and population levels the dental profession must help ensure that oral disease does not increase the burden of systemic disease.
1. Wang $Y C_{1}$ McPherson $\mathrm{K}$, Marsh $\mathrm{T}$, Gortmaker S L, Brown M. Health and economic burden of the projected obesity trends in the USA and the UK. Lancet 2011; 378: 815-825.

2. Diabetes UK. NHS spending on diabetes 'to reach 16.9 billion by 2035.' Diabetes UK, 2012. Online news article available at http://www.diabetes.org.uk/ About_us/News_Landing_Page/NHS-spending-ondiabetes-to-reach-169-billion-by-2035/ (accessed May 2013).

3. Matyka K A. Childhood obesity and type 2 diabetes In Barnett A H, Barnett T \& Kumar S (eds) Obesity and diabetes. 2nd ed. pp 221-240. Oxford: John Wiley \& Sons, 2009.

4. Caprio S. Development of type 2 diabetes mellitus in the obese adolescent: a growing challenge. Endocr Pract 2012; 18: 791-795.

5. Williams R C, Mahan C J. Periodontal disease and diabetes in young adults. J Am Med Assoc 1960; 172: 776-778.

6. Giannini C, Caprio S. Progression of $\beta$ cell dysfunction in obese youth. Curr Diab Rep 2012; Epub ahead of print

7. Belting C M, Hiniker J J, Dummett C O. Influence of diabetes on severity of periodontal disease. J Periodontol 1964; 35: 476-480.

8. Golomb I M. An evaluation of the relation of diabe tes mellitus to periodontal disease. NYState Dent $J$ 1949; 15: 525-528.

9. Suvan J, D'Aiuto F, Moles D R, Petrie A, Donos N. Association between overweight/obesity and periodontitis in adults. A systematic review. Obes Rev 2011; 12: e381-404

10. Freemantle N, Holmes J, Hockey A, Kumar S. How strong is the association between abdominal obesity and the incidence of type 2 diabetes? Int J Clin Pract 2008: 62: 1391-1139.

11. Field A E, Coakley E H, Must A et al. Impact of overweight on the risk of developing common chronic diseases during a 10-year period. Arch Intern Med 2001: 161: 1581-1586

12. Colditz G A, Willet W C, Rotnitzsy A, Manson J E. Weight gain as a risk factor for clinical diabetes mellitus in women. Ann Internal Med 1995. 122: 481-486.

13. Alberti G. Forward. In Barnett A H, Barnett T \& Kumar S (eds) Obesity and Diabetes, 2nd ed. pp xi. Oxford: John Wiley \& Sons, 2009.

14. Sherwin R, Jastreboff A M. Year in diabetes 2012: the diabetes tsunami. J Clin Endocrinol Metab 2012 97: 4, 293-301.

15. Dinarello C A. Proinflammatory cytokines. Chest 2000; 118: 503-508.

16. Ouchi N, Parker J L, Lugus J J, Walsh K. Adipokines in inflammation and metabolic disease. Nat Rev Immunol 2011; 11: 85-97.

17. Donath M Y, Shoelson S E. Type 2 diabetes as an inflammatory disease. Nat Rev Immunol 2011; 11: 98-107.

18. Shimizu I, Yoshida Y, Katsuno T, Minamino T. Adipose tissue inflammation in diabetes and heart failure. Microbes Infect 2013; 15: 11-17.

19. Perlstein M I, Bissada N F. Influence of obesity and hypertension on the severity of periodontitis in rats. Oral Surg Oral Med Oral Pathol 1977; 43: 707-719

20. Sheiham A, Stelle J G, Marcenes W, Finch S, Walls A W G. The relationship between oral health status and body mass index among older people: A national survey of older people in Great Britain. $\mathrm{Br}$ Dent J 2002: 192: 703-706.

21. Dahiya P, Kamal R, Gupta R. Obesity, periodontal and general health: Relationship and management. Indian J Endocr Metab 2012; 16: 88-93.

22. Chaffee B W, Weston S J. Association between chronic periodontal disease and obesity: a systematic review and meta-analysis. J Periodontol 2010; 81: 1708-1724

23. Kim E J, Jin B H, Bae K H. Periodontitis and obesity: a study of the Fourth Korean National Health and Nutrition Examination Survey. Obesity and oral disease - a challenge for dentistry. J Peridontal 2011; 82: 533-542.

24. Khader Y S, Bawadi H A, Haroun T F, Alomari M, Tayyem R F. The association between periodontal disease and obesity among adults in Jordan. J Clin Periodontol2009; 36: 18-24.

25. Saxlin T, Ylöstalo P, Suominen-Taipale L, Männistö $\mathrm{S}$, Knuuttila M. Association between periodontal infection and obesity: results of the Health 2000 Survey. J Clin Periodontol 2011; 38: 236-242.

26. Saxlin T, Ylöstalo P, Suominen-Taipale L, Aromaa A, Knuuttila M. Overweight and obesity weakly predict the development of periodontal infection. J Clin Periodontol2010: 37: 1059-1067.

27. Wood N, Johnson R B, Streckfus C F. Comparison of body composition and periodontal disease using nutritional assessment techniques: Third National Health and Nutrition Examination Survey (NHANES III). J Clin Periodontol 2003; 30: 321-327.

28. Saito T, Shimazaki Y, Koga T, Tsuzuki M, Ohshima A. Relationship between upper body obesity and periodontitis. J Dent Res 2001; 80: 1631-1636.

29. Al-Zahrani M S, Bissada N F, Borawskit E A. Obesity and periodontal disease in young, middle-aged, and older adults. J Periodontol 2003; 74: 610-615.

30. Reeves A F, Rees J M, Schiff M, Hujoel P. Total body weight and waist circumference associated with chronic periodontitis among adolescents in the United States. Arch Pediatr Adolesc Med 2006; 160: 894-899.

31. Dalla Vecchia C F, Susin C, Rösing C K, Oppermann R V, Albandar J M. Overweight and obesity as risk indicators for periodontitis in adults. Overweight and obesity as risk indicators for periodontitis in adults. J Periodontol 2005; 76: 1721-1728.

32. Modéer T, Blomberg C, Wondimu B, Lindberg TY, Marcus C. Association between obesity and periodontal risk indicators in adolescents. Int J Pediatr Obes 2011; 6: 264-270.

33. Ekuni D, Yamamoto T, Koyama R, Tsuneishi M, Naito $\mathrm{K}$, Tobe K. Relationship between body mass index and periodontitis in young Japanese adults. J Periodontal Res 2008; 43: 417-421.

34. Gorman A, Kaye E K, Apovian C, Fung T T, Nunn M, Garcia R I. Overweight and obesity predict time to periodontal disease progression in men. J Clin Periodonto/ 2012; 39: 107-114.

35. Jimenez M, Hu F B, Marino M, Li Y, Joshipura K J. Prospective associations between measures of adiposity and periodontal disease. Obesity (Silver Spring). 2012; 20: 1718-1725.

36. Morita I, Okamoto Y, Yoshii S et al. Five-year incidence of periodontal disease is related to body mass index. J Dent Res. 2011; 90: 199-202.

37. Page R C, Offenbacher S, Schroeder H E, Seymour $\mathrm{G} J$, Kornman K S. Advances in the pathogenesis of periodontitis: summary of developments, clinical implications and future directions. Periodontol 2000 1997; 14: 216-248.

38. Loe H. Periodontal disease. The sixth complication of diabetes mellitus. Diabetes Care 1993; 16: 329-334

39. Salvi G E, Carollo-Bittel B, Lang N P. Effects of diabetes mellitus on periodontal and peri-implant conditions: update on associations and risks. J Clin Periodonto/ 2008; 35: 398-409.

40. Chávarry N G, Vettore M V, Sansone C, Sheiham A. The relationship between diabetes mellitus and destructive periodontal disease: a meta-analysis. Oral Health Prev Dent 2009; 7: 107-127.

41. Mealey B L, Ocampo G L. Diabetes mellitus and periodontal disease. Periodontol 20002007 . 44: 127-153.

42. Cianciola L J, Park P H, Bruck E, Mosovich L, Genco $\mathrm{R} J$. Prevalence of periodontal disease in insulindependent mellitus (juvenile diabetes). J Am Dent Assoc 1982; 104: 653-660.

43. Lalla $E_{1}$ Cheng $B$, Lal $\mathrm{S}$ et al. Diabetes mellitus promotes periodontal destruction in children. $J$ Clin Periodonto/ 2007; 34: 294-298.

44. Manoucher-Pour M, Spagnuolo P J, Rodman H M, Bissada N F. Comparison of neutrophil chemotactic response in diabetic patients with mild and severe periodontal disease. J Periodontol 1981; 52: 410-415.

45. Lalla E, Lamster I B, Stern D M, Schmidt A M Receptor for advanced glycation end products, inflammation, and accelerated periodontal disease in diabetes: mechanisms and insights into 
therapeutic modalities. Ann Periodontol 2001; 6: 113-118.

46. Ramasamy $R$, Yan S F Schmidt A M. Receptor for AGE (RAGE): signalling mechanisms in the pathogenesis of diabetes and its complications. Ann NY Acad Sci 2011; 1243: 88-102.

47. Grossi S G, Genco R J. Periodontal disease and diabetes mellitus: A two-way relationship. Ann Periodontol 1998; 3: 51-61.

48. Taylor G W. Bidirectional interrelationships between diabetes and periodontal diseases: an epidemiologic perspective. Ann Periodontol 2001; 6: 99-112.

49. Nishimura F, Iwamoto $Y$, Mineshiba J, Shimizu A, Soga $Y$, Murayama Y. Periodontal disease and diabetes mellitus: the role of tumour necrosis factor-alpha in a 2 way relationship. J Periodontol 2003; 74: 97-102.

50. Genco R J, Grossi S G, Ho A, Nishimura F, Murayama $Y$. A proposed model linking inflammation to obesity, diabetes, and periodontal infections. J Periodontol 2005; 76(Suppl 11): 2075-2084.

51. Pischon N, Heng N, Bernimoulin J P, Kleber B M, Willich S N, Pischon T. Obesity, inflammation, and periodontal disease. J Dent Res 2007; 86: 400-409.

52. Demmer R T, Desvarieux M, Holtfreter B et al.
Periodontal status and $\mathrm{A} 1 \mathrm{C}$ change: longitudinal results from the study of health in Pomerania (SHIP). Diabetes Care 2010; 33: 1037-1043.

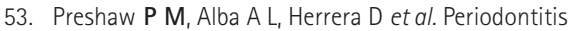
and diabetes: a two-way relationship. Diabetologia 2012; 55: 21-31.

54. Saito T, Shimazaki Y, Kiyohara Y et al. Relationship between obesity, glucose tolerance, and periodontal disease in Japanese women: the Hisayama study. J Periodontal Res 2005; 40: 346-353.

55. Cutler C W, Shinedling E A, Nunn M et al. Association between periodontitis and hyperlipidemia: cause or effect? J Periodontol 1999; 70: 1429-1434.

56. Cutler C W, lacopino A M. Periodontal disease: Links with serum lipid/triglyceride levels? Review and new data. J Int Acad Periodontol 2003; 5: 47-51.

57. Darré L, Vergnes J N, Gourdy P, Sixou M. Efficacy of periodontal treatment on glycaemic control in diabetic patients: A metaanalysis of interventional studies. Diabetes Metab 2008; 34: 497-506.

58. Simpson T C, Needleman I, Wild S H, Moles $D$ R, Mills E J. Treatment of periodontal disease for glycaemic control in people with diabetes. Cochrane Database Syst Rev 2010; CD004714.

59. Stratton I M, Adler A I, Neil H A et al. Association of glycaemia with macrovascular and microvascular complications of type 2 diabetes (UKPDS 35): prospective observational study. BMJ 2000 ; 321: 405-412.

60. Saremi A, Nelson R G, Tulloch-Reid M et al. Periodontal disease and mortality in type 2 diabetes. Diabetes Care 2005; 28: 27-32.

61. Chapple I L, Genco R J. Diabetes and periodontal diseases: consensus report of the Joint EFP/AAP Workshop on Periodontitis and Systemic Diseases. J Clin Periodonto/ 2013; 40 (Suppl 14): S106-S112.

62. Chapple I L, Genco R J. Diabetes and periodontal diseases: consensus report of the Joint EFP/AAP Workshop on Periodontitis and Systemic Diseases. J Periodontol 2013; 84 (Suppl 4): S106-S112.

63. Cullinan M P, Ford P J, Seymour G J. Periodontal disease and systemic health: current status. Aust Dent J 2009; 54 (Suppl 1): S62-69.

64. Lalla E, Kunzel C, Burkett S, Cheng B, Lamster I B. Identification of unrecognized diabetes and prediabetes in a dental setting. J Dent Res 2011; 90: 855-860.

65. Wang Y, Rimm E B, Stampfer M J, Willett W C, Hu F B. Comparison of abdominal adiposity and overall obesity in predicting risk of type 2 diabetes among men. Am J Clin Nutr 2005; 81: 555-563.

\section{Corrigendum}

\section{Practice article (BDJ 2013; 214: 551-557)}

'Caries detection and diagnosis, sealants and management of the possibly carious fissure' In the above practice article, the figure captions for Figures 2, 5 and 9 were incorrect. The correct figures captions are as follows: Fig. 2 Possibly carious occlusal fissure upper right first permanent molar (tooth 16)

Fig. 5 Bitewing radiograph of upper right 6 (16) seen in Figure 2

Fig. 9 A buccal pit in a lower right first permanent molar (tooth 46), which would benefit from having been sealed

The author apologises for any confusion caused. 